\title{
Effective fuel temperature of WWER-1000
}

\author{
Alexander Kudrov ${ }^{1 *}$, Arian Kuz'min ${ }^{1}$, and Yuri Rakov ${ }^{1}$ \\ ${ }^{1}$ National Research Tomsk Polytechnic University, 634050 Tomsk, Russia
}

\begin{abstract}
The main temperature characteristics of a pressurized water reactor are distinguished, supporting its safety and reliable operation. The special role of the uranium fuel effective temperature is emphasized and the accuracy of the analytical determination of the power effect is increased. The calculation of the temperature distribution along the radius of the fuel rod was carried out taking into account the temperature dependence of the thermal conductivity $\mathrm{UO}_{2}$. The design procedure was corrected for using the Finca-Ronchi dependence for the thermal conductivity of $95 \%$ density of the theoretical one.
\end{abstract}

\section{Introduction}

Safety operation of nuclear power plants is the reliability and efficiency of the individual components: staff, heat transfer equipment [1-6], characteristics of nuclear fuel [7] and many others.

They deserve special consideration of characteristics affecting the internal safety of a nuclear reactor: power and temperature reactivity effects $[8,9]$.

The temperature effect of reactivity (TER), which is defined by the difference of reactivity, caused by the same temperature change from the cold to the hot state of all materials in reactor core (RC). The initial temperature of the cold reactor is set to $20-40{ }^{\circ} \mathrm{C}$. Hot reactor temperature varies with a minimum controlled power level due to external heat sources. Fuel reactivity effect is responsible for forming the neutron spectrum and its leakage.

The power reactivity effect (PRE) $\rho_{\mathrm{N}}$ is determined by the mean or effective temperature of uranium fuel $T_{\text {eff }}$ and the actual presence an isotope ${ }^{238} \mathrm{U}$ in it. Due to the Doppler effect, there are resonance levels of the uranium isotope broadening with temperature rise, which increases the neutron absorption probability, thereby reducing reactivity. The higher the fuel temperature and the lower its concentration, the greater the effect. Also, magnitude $\rho_{\mathrm{N}}$ is important for to assess the mode extension fuel campaign using the power effect reactivity.

\section{Differential characteristics}

Isothermal $\alpha_{\mathrm{T}}=\mathrm{d} \rho / \mathrm{dT}$ and power $\alpha_{\mathrm{N}}=\mathrm{d} \rho_{\mathrm{N}} / \mathrm{dN}$ reactivity coefficients determine selfregulation, self-protection, reliability and safety of the nuclear reactor. Both coefficients to

\footnotetext{
* Corresponding author: alex12kudrow@gmail.com
} 
provide these nuclear reactor properties must be negative: the first is near the operative point, the second is on the entire range of power transient.

The fuel effective absolute temperature is determined by the exact integral formula

$$
T_{e f f}=\frac{\int_{0}^{r_{T}} T_{T}(r) 2 \pi r d r}{\int_{0}^{r_{T}} 2 \pi r d r}
$$

Or approximate expression [1]

$$
T_{\text {ef }}=T_{\mathrm{c}}+0.4\left(T_{\max }-T_{\mathrm{c}}\right)
$$

where

$T_{T}(r)$-temperature distributions over the fuel block;

$T_{\max }$ - temperatures on the axis of the fuel block;

$T_{c}$ - temperatures on the surface of the fuel block.

\section{Characteristic comparison on the coefficient of thermal conductivity}

The method of direct explicit calculation $T_{T}(r)$ using the $\lambda_{\mathrm{UO}_{2}}(T)$ is presented in handbooks $[10,11]$. Research activity was based on the results [12], where the theoretical dependence of the thermal conductivity $\mathrm{UO}_{2}$ was used as the equation:

$$
\lambda_{\mathrm{UO}_{2}}=\frac{10^{2}}{3.77+0.0258 \cdot T}+1.1 \cdot 10^{-4} \cdot T+1.01 \cdot 10^{-11} \cdot T^{3} \cdot \exp \left(7.2 \cdot 10^{-4} \cdot T\right)
$$

There is also the empirical formula:

$$
\lambda_{\mathrm{UO}_{2}}=11.5-1.14 \cdot 10^{-2} \cdot T+4.4 \cdot 10^{-6} T^{2}-5 \cdot 10^{-10} \cdot T^{3}
$$

which could be approximated by

$$
\lambda_{\mathrm{UO}_{2}}=\lambda_{a} \operatorname{ch}[(T-a) / b]
$$

choosing the constants: $\lambda_{a}=2,3 \mathrm{~W} /(\mathrm{m} \cdot \mathrm{K}) ; a=2000 \mathrm{~K} ; b=870 \mathrm{~K}$.

More recent works are recommended to use the Fink-Ronchy formula to determine the thermal conductivity with density of $95 \%$ :

$$
\lambda_{\mathrm{UO}_{2}}=\frac{100}{7.5408+17.692 \cdot \tau+3.6142 \cdot \tau^{2}}+\frac{6400}{\tau^{5 / 2}} \exp \left(-\frac{16.35}{\tau}\right)
$$

where

$$
\tau=(T / 1000) \mathrm{K} \text {. }
$$

The equations (3) - (6) are presented in Fig. 1 and show the necessity of the coefficients adjustment in dependence (5). 


\section{Updating of the design formula for the fuel block}

We take the Fink-Ronchy formula (6) as the main dependence for the coefficient of the thermal conductivity $\mathrm{UO}_{2}$ and approximate it by the trigonometric function (5)

$$
\lambda_{\mathrm{UO}_{2}}=\lambda^{*}{ }_{a} \operatorname{ch}\left[\left(T-a^{*}\right) / b^{*}\right]
$$

which has the following constants: $\lambda^{*}{ }_{a}=2,1 \mathrm{~W} /(\mathrm{m} \cdot \mathrm{K}) ; a^{*}=2070 \mathrm{~K} ; b^{*}=980 \mathrm{~K}$.

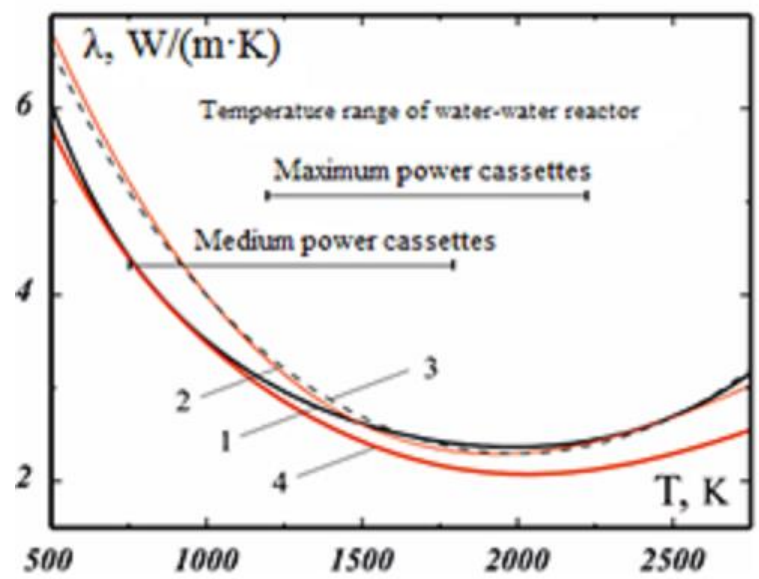

Fig. 1. Comparison of approximations using the thermal conductivity $\mathrm{UO}_{2}: 1-$ theoretical dependence (3) of work [12]; 2 - empirical formula (4), [12]; 3 - formula (5); 4 - Fink-Ronchi ratio (6).

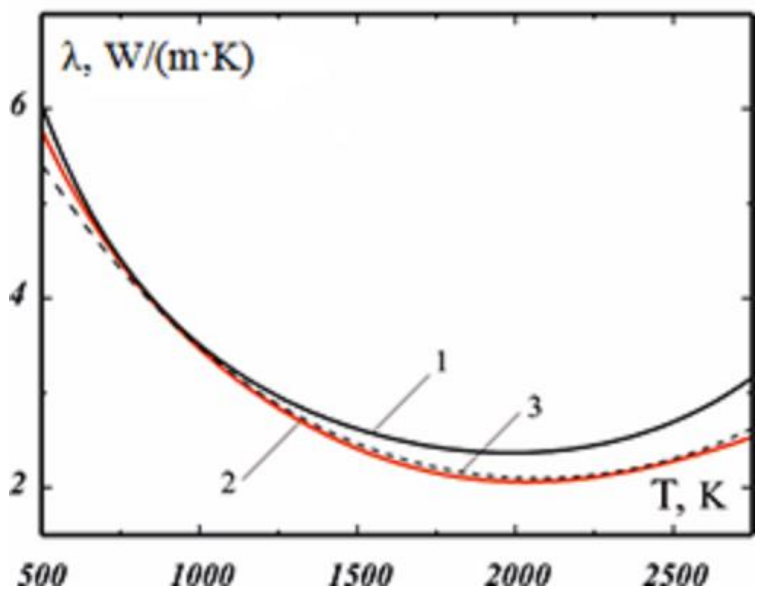

Fig. 2. Updating of approximation using the thermal conductivity $\mathrm{UO}_{2}: 1$ - theoretical dependence (3) of work [11]; 2 - Fink-Ronchi ratio (6); 3 - formula (7).

\section{Analysis of results}

Carrying out estimations on the proposed dependencies allows us to draw the following conclusions: 
- the approximation formula for determining the effective fuel temperature (2) is in error slightly more than $3 \%$;

- the acceptable trigonometric approximation (7) of the Fink-Ronchi formula has been received; it will allow calculating the radial temperature distribution using the temperature dependence of the uranium dioxide thermal conductivity (8);

- comparison with the known results of thermal design for the reactor fuel rods (WWER1000 [13]) showed slightly lower values of the temperature field; this indicates, first of all, the necessity of using the effect of density changes and deviations from stoichiometry, which requires further analysis.

\section{References}

1. O.S. Dmitrieva, I.N. Madyshev, A.V. Dmitriev, J. Eng. Phys. Thermophys., 90, 651 (2017), DOI: 10.1007/s10891-017-1612-z

2. A.V. Dmitriev, O.S. Dmitrieva, I.N. Madyshev, Thermal Engineering, 63, 674 (2016), DOI: $10.1134 / \mathrm{S} 0040601516080036$

3. A.M. Antonova, A.V. Vorobiev, A.S. Orlov, MATEC Web of Conf., 23, 01069 (2015), DOI: $10.1051 /$ matecconf $/ 20152301069$

4. A. Uvarov, A. Antonova, A. Vorobjev, MATEC Web of Conf., 37, 01062 (2015), DOI: 10.1051/matecconf/20153701062

5. S. Lavrinenko, P. Polikarpov, A. Matveeva, V. Martyshev, MATEC Web of Conf., 110, 01049 (2017), DOI: 10.1051/matecconf/201711001049

6. E. Pavelyev, S. Lavrinenko, MATEC Web of Conf., 72, 01085 (2016), DOI: 10.1051/matecconf/20167201085

7. V.A. Ruppel, Yu.S. Tretyakova, S.V. Lavrinenko, A.A. Matveeva, V.N. Martyshev, MATEC Web of Conf., 37, 01059 (2015), DOI: 10.1051/matecconf/20153701059

8. G.G. Bartholomew, G.A. Bat', V.D. Bajbakov, M.S. Alhutov, Fundamentals of the Theory and Methods for Calculating Nuclear Power Reactors (Energoizdat, Moscow, 1982) [in Russian]

9. V.I. Vladimirov, Physics of Nuclear Reactors: Practical Tasks for Their Operations (Knizhnyy dom "LIBROKOM", Moscow, 2009) [in Russian]

10. P.L. Kirillov, Yu.S. Yur'ev, V.P. Bobkov, Handbook of Thermohydraulic Calculations (Nuclear Reactors, Heat Exchangers, Steam Generators) (Energoizdat, Moscow, 1990) [in Russian]

11. P.L. Kirillov, A.V. Zhukov, N.I. Loginov, V.M. Makhin, I.L. Pioro, Yu.S Yur'ev, Handbook of Thermohydraulic Calculations in Nuclear Power. Volume 2. Nuclear Reactors, Heat Exchangers, Steam Generators (IzdAt, Moscow, 2013) [in Russian]

12. V.I. Kolyadin, E.P. Il'in, A.G. Kharlamov, V.V. Yakovlev, Atomic energy, 36 (1), 59 (1974)

13. A.M. Afrov, S.A. Andrushechko, V.F. Ukraintsev, Nuclear Fuel, 7, 178 (2006) 